|| ISSN(online): 2589-8698 || ISSN(print): 2589-868X || International Journal of Medical and Biomedical Studies

Available Online at www.ijmbs.info

PubMed (National Library of Medicine ID: 101738825)

Index Copernicus Value 2018: 75.71

Volume 3, Issue 4; April: 2019; Page No. 53-59

\title{
BIO-MEDICAL WASTE MANAGEMENT RULES 2016. ARE THE HEALTH CARE WORKERS AWARE? - EVALUATION OF AN INTERVENTION.
}

\author{
Arthi $\mathrm{M}^{1}$, Surendar $\mathrm{R}^{1}$, Srikanth $\mathrm{S}^{2}$, Latha $\mathrm{S}^{3}$, Radhika ${ }^{4}$ \\ ${ }^{1}$ Assistant Professor, Department of Community Medicine, SVMCH \& RC \\ ${ }^{2}$ Professor, Department of Community Medicine, SVMCH \& RC \\ ${ }^{3}$ Chief Nursing Officer, ICON \\ ${ }^{4}$ Post Graduate, Department of Community Medicine, SVMCH \& RC
}

Article Info: Received 18 March 2019; Accepted 03 April. 2019

Cite this article as: M, A., R, S., S, S., S, L., \& ., R. (2019). BIO-MEDICAL WASTE MANAGEMENT RULES 2016. ARE

THE HEALTH CARE WORKERS AWARE? - EVALUATION OF AN INTERVENTION. International Journal of Medical and Biomedical Studies, 3(4).

DOI: https://doi.org/10.32553/ijmbs.v3i4.183

Address for Correspondence: Dr. Arthi M, Department of Community Medicine, SVMCH \& RC, Puducherry Conflict of interest: No conflict of interest.

\section{Abstract}

Background: Biomedical waste has become a crucial health hazard in many countries including India. Careless and indiscriminate disposal of these wastes can contribute to the spread of serious diseases. The new guideline of Bio-Medical Waste Management Rules -2016 was released on March, 2016 and revised in 2018. In order to update the new rules periodically, the present study was carried out with the aim to assess the knowledge, attitude and practice on biomedical waste management among health care workers working in a tertiary hospital in Puducherry and to evaluate the effectiveness of sensitization program regarding 2016 Bio-medical waste management rules.

Methods: All staff nurses and nursing assistants working at SVMCH \& RC, Puducherry were included. Study period was between August and October 2016. About 103 willing participants were included. The participants were assessed by pre-test and post-test with a semi-structured questionnaire. Data analysed using SPSS (version 23). Descriptive and inferential statistics were used to compare pre-test and post-test score. Chi-square and Fisher's exact tests were applied to find the significant difference before and after intervention.

Results: Among total participants (103), 83.5\% of the participants were Staff Nurses, $10.7 \%$ Female Nursing Assistant and rest Auxiliary Nursing Mid-wife. About $68 \%$ of them have reported that it is the sole responsibility of the Government in proper management of Bio-medical waste and $27.2 \%$ of them reported that procedures involved in Bio-Medical Waste Management (BMWM) are increasing the financial burden of their hospital. Regarding identification of the symbol of bio-hazard, there was a significant increase in knowledge in the post-test when compared to the pre-test. About $40.8 \%(42)$ of participants had poor knowledge about BMW in pre test. Regarding attitude and practice, in the pretest, around $59 \%$ have said that they will report about any injury due to or during wrong disposal whereas in the post-test it has been increased to $78 \%$ which is statistically significant $(p<0.05)$. About $89.3 \%$ of the participants reported that they are having the practice of wearing gloves while handling BMW in pre-test whereas in the post-test, $94.2 \%$ has reported. Overall mean and standard deviation of 
pre-test and post-test scores regarding BMW shows a statistically significant improvement in KAP score regarding biomedical waste management and new rules in the post-test after intervention than the pre-test.

Conclusions: The knowledge of the participants regarding management of bio-medical waste is still in its childhood stage. There was an evident increase after administration of sensitisation program.

Keywords: Biomedical waste, Health care workers

\section{INTRODUCTION:}

Biomedical waste has become a crucial health hazard in many countries including India due to its major adverse effects to the environment caused by the hospital waste generated during patient care. Due to advancement of health care services and increased patients load, the medical institutes are generating large amount of medical wastes. Careless and indiscriminate disposal of these wastes can contribute to the spread of serious diseases such as hepatitis and AIDS (HIV) among those who handle it as well as the public. ${ }^{1}$ This has made Biomedical Waste Management as an emerging issue of major concern not only to the hospitals and nursing home authorities, but also to the environment.

In many developing, they strictly follow the rules for collection, segregation, storage and disposal of hospital waste whereas in India, much attention has not been paid to the management of biomedical waste. Inadequate segregation leads to contamination of hospital wastes with general waste making it more hazardous. The awareness regarding biomedical waste management is very less among health personnel in India which makes the implementation of biomedical waste management unsatisfactory as some hospitals are disposing the waste in a haphazard, improper and indiscriminate manner. ${ }^{2}$ The new guideline of Bio-Medical Waste Management Rules -2016 was released on March, $2016 .^{3}$

One of India's major focuses is to change the attitude of the health care personnel including staff nurses and other health care workers to incorporate proper biomedical waste management practices in their daily work. So, awareness about various aspects of biomedical waste management isrequired to be assessed among the health personnel and there is a need to update the new rules periodically. Several studies had also recommended that periodical sensitization program will be helpful to ascertain proper management of biomedical waste. $4,5,6$ Taking all these aspects to an account, the present study was carried out with the aim to assess the knowledge, attitude and practice on biomedical waste management among health care workers working in a tertiary hospital in Puducherry and to evaluate the effectiveness of sensitisation program regarding 2016 Biomedical waste management rules.

\section{METHODOLOGY}

The study was conducted among all staff nurses and nursing assistants between August and October 2016 at SVMCH \& RC, Puducherry. After obtaining Ethical clearance, about 103 willing participants from various working sections like wards, Operation Theatres, Intensive Care Units, Haemodialysis units, Endoscopy, Emergency unit and procedure room were included. The participants were assessed by pre-test and posttest. For this purpose, a pre-designed, pre-tested semi-structured questionnaire from the new guidelines on Bio-Medical Waste Management Rules -2016 was prepared. Content Validity was done with the help of experts. It contains 20 multiple choice questions including knowledge, attitude and practices regarding generation, storage, collection, transportation and disposal of biomedical waste. Following the pre-test, a sensitization program was conducted to the participants using Audio-Visual aids. The program was regarding categories of waste and segregation, collection and treatment of biomedical waste, final disposal and safety measures as mentioned in 2016 guidelines. After 
this, the participants were observed for change in practices. At an interval of one week, post-test was conducted with the same questions.

\section{STATISTICAL ANALYSIS:}

Data were compiled and analysis using SPSS (version 23). Each correct answer was given a score of one and wrong answer or unanswered was given a score of zero. The highest knowledge score would be 16. For interpretations, the scores were distributed as follows; Poor knowledge $\leq 50 \%$, Average knowledge $51-75 \%$, Good knowledge > $75 \%$. Descriptive and inferential statistics were used and compared with the pre-test and post-test score. tests were applied to find the significant difference before and after intervention.

\section{RESULTS:}

Among total participants (103), females were $95 \%$ (98) and rest males. More than half of them $(51.5 \%)$ were $<25$ years, $28.2 \%$ were between 25-30 years and very few (4.9\%) were $>35$ years of age. About $83.5 \%$ of the participants were Staff Nurses, $10.7 \%$ Female Nursing Assistant and rest Auxiliary Nursing Mid-wife. About $68 \%$ of them had working experience of 1-5 years. 11.7 $\%$ had $5-10$ and $9.7 \%$ had $>10$ years of experiences respectively. Among the staff nurses were $49.5 \%$ had completed B.Sc, $28.1 \%$ Diploma and $5.9 \%$ had completed PB.Sc courses (Table 1)

Fifty nine participants reported that Nurses are responsible for improper disposal and 29 of them reported that patients and attendees were responsible. Five of them reported that Doctors were responsible (Fig 1).

Seventy two participants reported that improper disposal was mainly due to lack of knowledge, 20 persons reported due to laziness, 4 people reported that was due to Unwillingness and deliberate (Fig 2). About $68 \%$ of them have reported that it is the sole responsibility of the Government in proper management of Biomedical waste and $27.2 \%$ of them reported that procedures involved in Bio-Medical Waste
Management (BMWM) are increasing the financial burden of their hospital.

Knowledge assessment on BMWM among health care workers in the pre-test and in the post-test after intervention shows that in the pre-test,the contents of the BMWM were answered correctly by $36.9 \%$ of the total participants while in the post-test nearly half of the participants (46.6\%) answered correctly. The knowledge of the participants has been improved especially in categorising the bio-medical waste, maximum duration of storage of BMW and new categories of bio-medical waste which was statistically significant $(p<0.001)$. Regarding identification of the symbol of bio-hazard, there was a significant increase in knowledge in the post-test when compared to the pre-test. Around half of the study population in the pre-test, were aware of the colour codes in New BMWM Rules-2016, whereas it has improved to $75 \%$ the post-test. (Table 2)

Regarding attitude and practice, around $93 \%$ in the pre-test have reported that Bio Medical Waste Managementis a teamwork whereas in the post-test all participants accepted. In the pre-test, around $59 \%$ have said that they will report about any injury due to or during wrong disposal whereas in the post-test it has been increased to $78 \%$ which is statistically significant $(p<0.05)$. About $89.3 \%$ of the participants reported that they are having the practice of wearing gloves while handling BMW in pre-test whereas in the post-test, $94.2 \%$ has reported. (Table 3)

About40.8\% (42) of participants had poor knowledge about BMW in pre test. Very few participants $1.9 \%$ (2) had good knowledge whereas the score increased to $20.4 \%$ in post test. It was seen that the score was average for $68.9 \%$ in the post-test. Overall there was a significant change in their knowledge (Table 4).

Overall mean and standard deviation of pre-test and post-test scores regarding BMW shows a statistically significant improvement in KAP score regarding biomedical waste management and 
new rules in the post-test after intervention than the pre-test. (Table 5)

Table 1: SOCIO-DEMOGRAPHIC CHARACTERISTIC OF THE HEALTH CARE WORKERS ( $n=103$ )

\begin{tabular}{|c|c|}
\hline Parameters & $n(\%)$ \\
\hline \multicolumn{2}{|l|}{ Age in years } \\
\hline$<25$ & $53(51.5)$ \\
\hline $25-30$ & $29(28.2)$ \\
\hline $31-35$ & $16(15.5)$ \\
\hline$>35$ & $5(4.9)$ \\
\hline \multicolumn{2}{|l|}{ Designation } \\
\hline Auxiliary Nursing Midwives & $6(5.8)$ \\
\hline Female Nursing Assistant & $11(10.7)$ \\
\hline Staff Nurse & $86(83.5)$ \\
\hline \multicolumn{2}{|l|}{ Place of Work } \\
\hline Out-Patient Department & $25(24.3)$ \\
\hline Operation Theatre & $13(12.6)$ \\
\hline Wards & $65(63.1)$ \\
\hline \multicolumn{2}{|l|}{ Years of Experience } \\
\hline$<1$ & $11(10.7)$ \\
\hline $1-5$ & $70(68.0)$ \\
\hline $6-10$ & $12(11.7)$ \\
\hline$>10$ & $10(9.7)$ \\
\hline
\end{tabular}

TABLE 2: ASSESSMENT OF KNOWLEDGE ON BMWM AMONG HEALTHCARE WORKERS BEFORE AND AFTER INTERVENTION

\begin{tabular}{|c|c|c|c|c|c|}
\hline \multicolumn{2}{|l|}{ Attitude, Practise Assessment } & $\begin{array}{l}\text { Pre-test } \\
\mathbf{N}(\%)\end{array}$ & $\begin{array}{l}\text { Post-test } \\
\text { N (\%) }\end{array}$ & Chi-Square & p-value \\
\hline \multirow{2}{*}{ Do you think it is an Extra burden? } & Yes & $24(23.3)$ & $79(76.7)$ & \multirow{2}{*}{.000} & \multirow{2}{*}{1.000} \\
\hline & No & $79(76.7)$ & $24(23.3)$ & & \\
\hline \multirow{2}{*}{ Do you think it isa teamwork? } & Yes & $96(93.2)$ & $103(100)$ & \multirow{2}{*}{7.246} & \multirow{2}{*}{0.014} \\
\hline & No & $7(6.8)$ & $0(0)$ & & \\
\hline \multirow{2}{*}{$\begin{array}{l}\text { Do you think there is a change in } \\
\text { categories in new rule? }\end{array}$} & Yes & $32(31.1)$ & $80(77.7)$ & \multirow{2}{*}{45.082} & \multirow{2}{*}{0.000} \\
\hline & No & $71(68.9)$ & $23(22.3)$ & & \\
\hline \multirow{2}{*}{$\begin{array}{l}\text { Will u combine unidentified waste } \\
\text { with BMW? }\end{array}$} & Yes & $25(24.3)$ & 37 (35.9) & \multirow{2}{*}{3.323} & \multirow{2}{*}{0.068} \\
\hline & No & $78(75.7)$ & $66(64.1)$ & & \\
\hline \multirow{2}{*}{ Have you vaccinated when injured? } & Yes & $60(58.3)$ & $70(68.0)$ & \multirow{2}{*}{2.085} & \multirow{2}{*}{0.149} \\
\hline & No & $43(41.7)$ & $33(32.0)$ & & \\
\hline \multirow{2}{*}{ Will you report? } & Yes & $61(59.2)$ & $80(77.7)$ & \multirow{2}{*}{8.114} & \multirow{2}{*}{0.004} \\
\hline & No & $42(40.8)$ & $23(22.3)$ & & \\
\hline \multirow{2}{*}{$\begin{array}{l}\text { Are you wearing gloves while } \\
\text { handling BMW }\end{array}$} & Yes & $92(89.3)$ & $97(94.2)$ & \multirow{2}{*}{1.603} & \multirow{2}{*}{0.205} \\
\hline & No & $11(10.7)$ & $6(5.8)$ & & \\
\hline
\end{tabular}


TABLE 3: ASSESSMENT OF ATTITUDE, PRACTICE ON BMWM AMONG HEALTH CARE WORKERS BEFORE AND AFTER INTERVENTION

\begin{tabular}{|c|c|c|c|c|c|}
\hline \multicolumn{2}{|l|}{ Knowledge assessment } & $\begin{array}{c}\text { Pre-test } \\
\text { N (\%) }\end{array}$ & $\begin{array}{c}\text { Post-test } \\
\text { N (\%) }\end{array}$ & Chi-Square & p-value \\
\hline \multirow{2}{*}{ Contents of Bio-Medical Waste } & Correct & $38(36.9)$ & $48(46.6)$ & \multirow{2}{*}{1.996} & \multirow{2}{*}{0.102} \\
\hline & Wrong & $65(63.1)$ & $55(53.4)$ & & \\
\hline \multirow{2}{*}{ Categories of BMW } & Correct & $45(43.7)$ & $90(87.4)$ & \multirow{2}{*}{43.521} & \multirow{2}{*}{0.000} \\
\hline & Wrong & $58(56.3)$ & $13(12.6)$ & & \\
\hline \multirow{2}{*}{ Infection while handling BMW } & Correct & $64(62.1)$ & 73 (70.9) & \multirow{2}{*}{1.765} & \multirow{2}{*}{0.184} \\
\hline & Wrong & $39(37.9)$ & $30(29.1)$ & & \\
\hline \multirow{2}{*}{ Process of separating BMW } & Correct & $59(57.3)$ & $76(73.8)$ & \multirow{2}{*}{6.211} & \multirow{2}{*}{0.013} \\
\hline & Wrong & $44(42.7)$ & $27(26.2)$ & & \\
\hline \multirow{2}{*}{ Maximum time of storage } & Correct & $12(11.7)$ & $54(52.4)$ & \multirow{2}{*}{39.327} & \multirow{2}{*}{0.000} \\
\hline & Wrong & $91(88.3)$ & $49(47.6)$ & & \\
\hline \multirow{2}{*}{ Identification of General waste } & Correct & $57(55.3)$ & $60(58.3)$ & \multirow{2}{*}{0.178} & \multirow{2}{*}{0.673} \\
\hline & Wrong & $46(44.7)$ & $43(41.7)$ & & \\
\hline \multirow{2}{*}{ Symbol of Bio-Hazard } & Correct & $86(83.5)$ & $96(93.2)$ & \multirow{2}{*}{4.716} & \multirow{2}{*}{0.030} \\
\hline & Wrong & $17(16.5)$ & $07(6.8)$ & & \\
\hline \multirow{2}{*}{ Barcode } & Correct & $44(42.7)$ & $64(62.1)$ & \multirow{2}{*}{7.785} & \multirow{2}{*}{0.001} \\
\hline & Wrong & $59(57.3)$ & 39 (37.9) & & \\
\hline \multirow{2}{*}{ New Rules 2016} & Correct & $52(50.5)$ & $76(73.8)$ & \multirow{2}{*}{11.885} & \multirow{2}{*}{0.001} \\
\hline & Wrong & $51(49.5)$ & $27(26.2)$ & & \\
\hline
\end{tabular}

TABLE 4: CHANGE IN THE KAP SCORE BEFORE AND AFTER SENSITIZATION PROGRAM

\begin{tabular}{|l|c|c|c|c|}
\hline \multicolumn{1}{|c|}{ KAP score } & $\begin{array}{c}\text { Pre-test } \\
\text { N (\%) }\end{array}$ & $\begin{array}{c}\text { Post-test } \\
\text { N (\%) }\end{array}$ & \multirow{2}{*}{ Chi-Square } & p-value \\
\cline { 1 - 2 } Poor (0-7) & $42(40.8)$ & $11(10.7)$ & \multirow{2}{*}{14.338} & \multirow{2}{*}{.001} \\
\cline { 1 - 3 } Average (8-11) & $59(57.3)$ & $71(68.9)$ & & \\
\cline { 1 - 3 } Good (12-16) & $21(1.9)$ & $21(20.4)$ & & \\
\hline
\end{tabular}

TABLE 5: MEAN AND STANDARD DEVIATION OF TOTAL KAP SCORES OF PARTICIPANTS REGARDING BMW

\begin{tabular}{|l|c|c|c|c|}
\hline KAP scores & Mean & Std. Deviation & p-value & t-test \\
\hline Pre-test & 7.9417 & 2.06 & \multirow{2}{*}{.000} & -1.23301 \\
\hline Post-test & 9.1748 & 1.84 & & \\
\hline
\end{tabular}

\begin{tabular}{|l|}
$\square$ Nurses \\
Doctors \\
Patients and \\
attenders \\
All above
\end{tabular}

Figure 1: Person responsible for improper disposal 


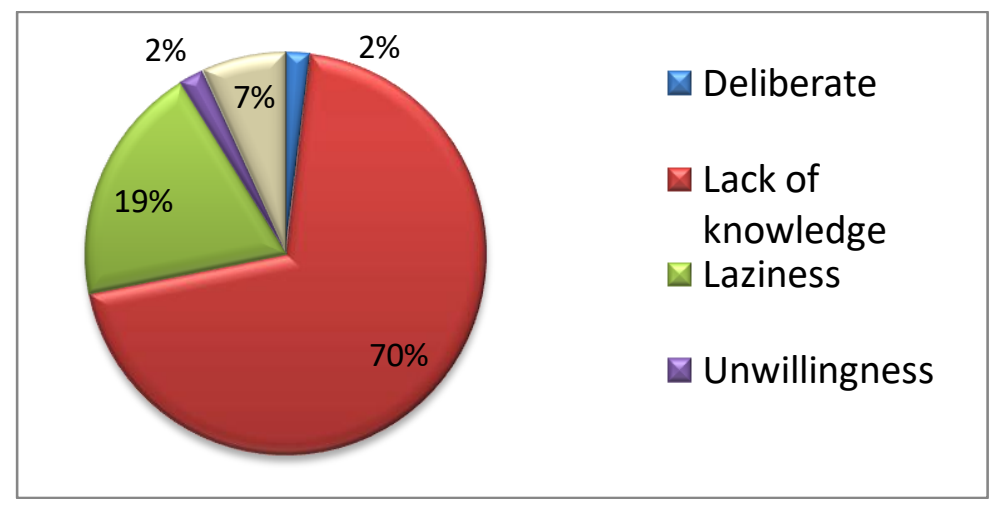

Figure 2: Reasons for wrong disposal

\section{DISCUSSION}

Our study has observed inadequate knowledge and poor practices among Health Care workers regarding new BMWM. This study had shown that before the introduction of the sensitisation program, only very few2 (1.9) were having good knowledge. But, after administering the teaching program, majority of the health care workers, 21 (20.4) were having good knowledge regarding BMW and the rest, 71 (68.9) were having average knowledge regarding BMW. This revealed that the there is lack of appropriate information and updates regarding BMW management among the health care workers. This finding was supported by similar study done in Uttar Pradesh with aim to assess the knowledge of hospital staff regarding BMW management in tertiary hospital by Imtaiz $D$ et. Al showing that the training was given to the nursing staff in which majority i.e. 159 (78.4\%) nurses were having average knowledge and 23 (11.3\%) nurses were having good knowledge whereas $21(10.3 \%)$ were having poor knowledge, it is evident that after the training, 108 (52.8\%) were having good knowledge and the rest 95(47.2\%) were having average knowledge. ${ }^{7}$

Similar study conducted in PHCs of Bangalore showed that the mean value of knowledge during the pre test was 36.70 which was increased to post test mean 86.70 with t-test value 14.04 and $p$ value $<0.0001$ which was considered as extremely significant. Thus indicate that video assisted teaching was effective. ${ }^{8}$ Our study also depicts that the mean knowledge score had increased after sensitisation program than before i.e. pre test knowledge mean was 7.9417 and post test mean was 9.1748 with $t$ value-1.23301 giving $p$ value $<0.001$ which is considered extremely significant, indicates significant improvement in knowledge regarding BMW. Similar result was shown in the study done by Tukaram et al. where the pre test knowledge mean was 17.383 and post test mean was 26.033 with $t$ value 12.497 giving $p$ value $<0.001$. $^{9}$,

\section{CONCLUSION}

Based on the results of the study it was shown that the knowledge on management of biomedical waste is still in its childhood stage. There was an evident increase in the knowledge scores among health care workers in the study after administration of sensitisation program. Hence they should be given an opportunity to update their knowledge regarding bio-medical waste management so that the importance of training needs importance, since lack of complete and proper knowledge about biomedical waste management impacts the practices of proper waste disposal. For this, there is a need for intensive sensitisation and training programs at regular time interval to repeatedly train and retrain all the staff nurses, which may include question raising and problem solving approach. This should be inspected and monitored periodically by Hospital Infection Control Committee.

\section{DECLARATIONS}




\section{Funding: No funding sources}

Ethical approval: The study was approved by the Institutional Ethics Committee

\section{REFERENCES}

1. Park K. Park's textbook of preventive and social Medicine. $22^{\text {nd }}$ ed, Jabalpur: BanarsidasBhanot; 2013:565

2. WHO, (1999). Guidelines for safe disposal of unwanted pharmaceuticals in and after emergencies. Essential Drugs and Other Medicines Department, World Health Organization, Avenue Appia 20, $\mathrm{CH}-1211$ Geneva 27, Switzerland.

3. Ministry of. Environment, forest and climate change. Government of India. Bio-Medical Waste Management Rules, 2016.

4. DeoD, Tak S B, Munde S S. "A Study of Knowledge Regarding Biomedical Waste Management among Employees of a Teaching Hospital in Rural Area". Journal of ISHWM. 2006 April; 5(1): 12-5.

5. Mathur V, Dwivedi S, Hassan MA, Misra RP. Knowledge, attitude, and practices about biomedical waste management among healthcare personnel: A cross-sectional study. Indian J Community Med 2011;36: $143-5$
6. Mir, Rafiq et al. (2013) knowledge attitude and practices of biomedical waste management in SKIMS Medical College. IOSR Journal of nursing and Health science.1(5). 1940-2320

7. Imtaiz D et. Al. Assessment of Knowledge of Hospital Staff Regarding Biomedical Waste Management in a Tertiary Care Hospital in Uttar Pradesh. Scholars Journal of Applied Medical Sciences (SJAMS). 2014; 2(3C):107074.

8. Joylene Lolita Soares (2013). Effectiveness of video assisted teaching on knowledge and attitude regarding infection control and use of personal protective equipment among Junior health assistants at selected PHC"s, Bengaluru, India.

9. TukaramZagade, Asha Pratinidhi. Effectiveness of Educational Intervention on Knowledge and Practice among Bio-Medical Waste Handlers. International Journal of Science and Research (IJSR). 2014 May;3(5):285-95.

10. Asha Pratinidhi, TukaramZagade, Satish V Kakade. Effectiveness of Educational Intervention on Practice among Biomedical Waste Handlers" International Journal of science and Research Volume 3 Issue 8, August 2014: 1885- 91. 